\title{
Modeling the Barrier-Layer Formation in the Southeastern Arabian Sea*
}

\author{
F. Durand,${ }^{+}$D. Shankar, ${ }^{\#}$ C. De Boyer Montégut,${ }^{@}$ S. S. C. Shenoi, ${ }^{\#}$ B. Blanke, $\stackrel{\&}{\text { And }}$ \\ G. MADEC@ \\ + IRD, LEGOS, UMR5566 CNRS-CNES-IRD-UPS, Toulouse, France \\ \# Physical Oceanography Division, National Institute of Oceanography, Dona Paula, Goa, India \\ @ Laboratoire d'Océanographie et de Climatologie: Expérimentation et Analyses Numériques, Université Pierre et Marie Curie, \\ Paris, France \\ \& Laboratoire de Physique des Océans, UFR Sciences et Techniques, Brest, France
}

(Manuscript received 14 April 2005, in final form 26 October 2005)

\begin{abstract}
The effect of salinity on the formation of the barrier layer (BL) in the southeastern Arabian Sea (SEAS) is investigated using an ocean general circulation model. In accordance with previous studies, the runoff distribution and the India-Sri Lanka passage have a strong impact on the realism of the salinity simulated in the area at seasonal time scales. The model simulates a BL pattern in fairly good agreement with available observations. Eulerian and Lagrangian approaches show that the BL is formed by two complementary processes, the arrival of low-salinity surface waters that are cooled en route to the SEAS and downwelling of waters mostly local to the SEAS in the subsurface layers. The surface waters are partly of Bay of Bengal origin and are partly from the SEAS, but are cooled east and south of Sri Lanka in the model. That the downwelled subsurface waters are warm and are not cooled leads to temperature inversions in the BL. The main forcing for this appears to be remotely forced planetary waves.
\end{abstract}

\section{Introduction}

The southeastern Arabian Sea (SEAS; Fig. 1) presents a peculiar thermodynamic structure. First, it exhibits one of the highest sea surface salinity (SSS) variabilities observed, with a typical drop of 1.5 psu from October to March, and vice versa during the opposite season (Delcroix et al. 2005). The drop in salinity can be as high as 3.4 psu following a good monsoon (Gopalakrishna et al. 2005). Second, it becomes the warmest area of the World Ocean in April-May, prior to the onset of the summer monsoon over the Indian subcontinent (Joseph 1990). At this time, sea surface temperature (SST) exceeds $30^{\circ} \mathrm{C}$ (Rao and Sivakumar 1999, hereafter RS99). This "warm pool" plays a prominent role in the northern Indian Ocean-summer monsoon coupled system. Joseph (1990) pointed out that the

\footnotetext{
* National Institute of Oceanography Contribution Number 4073.

Corresponding author address: F. Durand, IRD, LEGOS, UMR5566 CNRS-CNES-IRD-UPS, 14 Avenue Edouard Belin, 31400 Toulouse, France.

E-mail: fabien.durand@ird.fr
}

DOI: $10.1175 / J C L I 4112.1$

(C) 2007 American Meteorological Society time of onset of the summer monsoon over India depends on the prevailing SSTs in the northern Indian Ocean. It turns out that the high SSS variability in the SEAS, the buildup of high SSTs, and monsoon onset are intimately linked. Masson et al. (2005) analyzed two state-of-the-art coupled ocean-atmosphere general circulation model outputs, differing only in the way salinity effects on ocean dynamics are modeled. They showed that the vertical profile of salinity in the SEAS is likely to govern the date of onset of the summer monsoon.

The processes underlying this ocean-atmosphere coupling have long been suggested by various authors. RS99 showed that the near-surface stratification owing to the arrival of low-salinity water in the SEAS from the Bay of Bengal in winter is important for the buildup of the warm pool in the SEAS during spring. Shenoi et al. $(1999,2005)$ provided a unified picture of the dynamics and thermodynamics of the SEAS. They showed that the SST maximum in the SEAS in April has its origin about six months earlier in the northern Bay of Bengal. Downwelling coastal Kelvin wave packets, generated by the collapse of the summer monsoon winds in the northern Bay of Bengal, force a current 


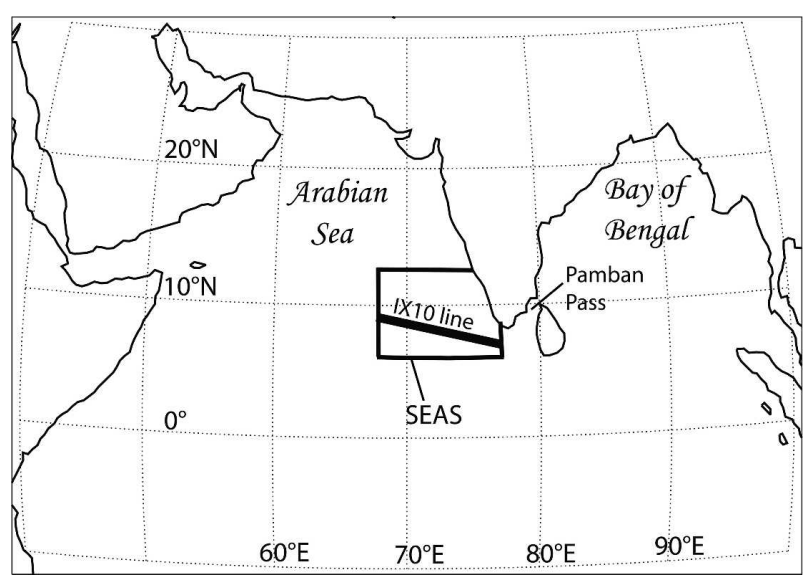

FIG. 1. Geography of the area.

that brings low-salinity water from the bay to the SEAS in November-January. They also trigger downwelling Rossby waves along the west coast of India; these waves propagate westward and cross the SEAS. Both the downwelling and the salinity-induced stable stratification at the surface are conducive to the formation of an SST high in spring. RS99 also demonstrated that the stratification of the near-surface layer in the SEAS in November-February traps the incoming heat fluxes in the thin surface mixed layer, thereby increasing drastically the SST in March-April.

A link between the peculiar temperature and salinity structures of the SEAS can be inferred from the observations reported by Thadathil and Gosh (1992, hereafter TG92). They noted the existence of a marked temperature inversion in the upper ocean during winter. A stable inversion can only be sustained by a sharp haline stratification, known as the barrier layer (BL) (Lukas and Lindstrom 1991); XBT and surface salinity data suggest that the depth of occurrence of inversions depends on salinity, with lower-surface salinity occurring along with shallower inversions (Gopalakrishna et al. 2005). The numerical modeling study of Durand et al. (2004, hereafter D04) showed that the temperature inversion in the SEAS is responsible for the SST rise in the initial stages of the formation of the SST high. Indeed, the energy trapped within the temperature inversion is reinjected into the surface layer during November-March via vertical processes, leading to an increase in SST. As regards the northern Indian Ocean-summer monsoon coupled system, this latter result and that of Masson et al. (2005) give a prominent role to the saltstratified barrier layer of the SEAS. From in situ measurements harvested during Arabian Sea Monsoon Experiment (ARMEX) surveys, Shankar et al. (2004) showed that the temperature inversions and the accom- panying low-salinity surface layer first occurred on the eastern side of the SEAS, then spread westward. Using high-frequency CTD casts, Shenoi et al. (2004) showed that both remotely forced upwelling and inflow of highsalinity Arabian seawater destroys the SEAS BL in late May. Therefore the missing piece of the complete story consists of the formation mechanism of the BL. This forms the major objective of the present paper.

Given the scarcity of the available temperature and salinity subsurface observations in the SEAS, investigating the BL formation calls for the use of a sophisticated numerical model with good mixed-layer physics. The model should be capable of simulating a realistic seasonal cycle of currents, temperature, and salinity in the upper ocean. Modeling the observed patterns of SEAS SSS has been a challenge for modelers (e.g., Han et al. 2001; Jensen 2001). In particular, it appears very difficult to reproduce the observed northward inflow of Bay of Bengal low-salinity water along the Indian west coast in winter (Han and McCreary 2001). Hence, in section 2, we present a series of numerical experiments that we carried out in order to improve our model's ability to simulate the seasonal cycle of salinity in the SEAS. Then we assess the BL features simulated by the model (section 3) and analyze mechanism underlying the formation of the BL (section 4). Section 5 concludes the study.

\section{The model and its salinity field}

\section{a. The model}

Our model is the Océan Parallélisé (OPA) ocean general circulation model (OGCM) (Madec et al. 1998) with $0.5^{\circ}$ horizontal resolution and 10 -m vertical resolution in the upper $120 \mathrm{~m}$. The model bathymetry results from an interpolation of ETOPO5 (Smith and Sandwell 1994) onto the model grid. The deepest layer thickness follows a partial-step formulation. The model is very similar to the version used by de Boyer Montégut et al. (2007b), except that we consider a domain limited to the tropical Indian Ocean. Our domain has closed boundaries along $34^{\circ} \mathrm{S}$ and $115^{\circ} \mathrm{E}$. A strong relaxation to Levitus (1998) temperature and salinity climatology is introduced at the boundaries. The vertical physics is based on a prognostic equation for the turbulent kinetic energy (Blanke and Delecluse 1993). The atmospheric boundary conditions include surface fluxes of momentum, heat, and freshwater. The momentum and precipitation fluxes are prescribed; all other fluxes (heat and evaporation) are diagnosed from specified atmospheric variables through bulk formulas. The model salinity is not restored to any climatology. Our forcing strategy consists of simulating the response 
of the model to the seasonal cycle of the atmospheric fluxes. It is forced by the seasonal climatologies of $\mathrm{Eu}$ ropean Remote Sensing Satellite-1 and -2 (ERS-1-2) wind stress (Bentamy et al. 1996) and Climate Prediction Center (CPC) Merged Analysis of Precipitation (CMAP) precipitation flux (Xie and Arkin 1997). The heat and evaporation fluxes are diagnosed from $\mathrm{Na}-$ tional Centers for Environmental Prediction (NCEP) reanalysis (Kalnay et al. 1996) air temperature. All fluxes are averaged over 1993-99. All model outputs subsequently presented concern the sixth year of the model spinup. Extensive validations of our simulation (not shown) revealed that it successfully reproduces the observed patterns of monsoon circulation as well as basin-scale thermohaline structure of the upper northern Indian Ocean. In particular, the premonsoonal rise of SST in the Arabian Sea closely follows the composite of Reynolds and Smith (1994) SST presented in D04, without any appreciable bias (not shown).

\section{b. Validation of the model SSS}

Since our study is focused on the upper-ocean salinity effects, a preliminary assessment of the realism of the salinity modeled at seasonal time scales in the SEAS is required. The following subsections present a hierarchy of simulations that we carried out in order to improve the modeled SSS. Figure 2 (top row) presents the monthly estimates of Levitus (1998) SSS from November to January. This climatology exhibits the wellknown contrast between the fresher Bay of Bengal waters (salinity in the range 33-34 psu in the southern part of the bay) and the saltier Arabian Sea waters (35-36 psu). Superimposed on this large-scale permanent gradient, we clearly see the gradual inflow of Bay of Bengal water into the SEAS over the period, as illustrated by the location of the 34-psu surface isohaline. The inflow has been documented in the literature (Shenoi et al. 1999; Jensen 2001). It appears to be driven by the East India Coastal Current (EICC) flowing equatorward and the West India Coastal Current flowing poleward (McCreary et al. 1993; Shetye et al. 1991, 1996). One must be cautious as regards to the pattern of the freshening tongue in the SEAS exhibited by the Levitus (1998) dataset. Indeed, the study by Delcroix et al. (2005) shows that the space scales of SSS variability in the SEAS are somewhat smaller than the correlation scales used by Levitus (1998) in his mapping scheme. As a result, one should expect the Levitus analysis to be unrealistically smooth in the area.

\section{1) The Default Run}

We first run the model using the default bathymetry and the UNESCO (1996) runoff. We named this first run "Default" (DEF) because these choices have been commonly made in previous modeling studies of the area (e.g., Han and McCreary 2001; Shankar et al. 2002; de Boyer Montégut et al. 2007b). The model reproduces fairly well the observed SSS features, with a large-scale gradient between Bay of Bengal and Arabian Sea (Fig. 2, second row). The timing of the inflow of Bay of Bengal freshwaters into the SEAS appears satisfactory as well. As in D04, we define the SEAS area as the box $\left(6^{\circ}-15^{\circ} \mathrm{N}, 68^{\circ}-77^{\circ} \mathrm{E}\right)$ (Fig. 1). Over this area, the rootmean-square difference (RMSD) between Levitus (1998) SSS and DEF SSS over the year is 0.68 psu. Given the likely uncertainties in Levitus (1998) SSS, we also validate the model SSS against other data. An observed climatology of SSS along IX10 thermosalinograph track has been computed as part of the French Observatoire de Recherche pour l'Environnement dedicated to SSS (Delcroix et al. 2005; data available online at www.legos.obs-mip.fr/en/observations/sss/). The track crosses the southern part of the SEAS box (Fig. 1). The asset of this along-track climatology is that the data coverage is much more satisfactory, given the small size of the SEAS, than in the gridded field of Levitus (1998). Hence, validating the model SSS against this along-track climatology is more meaningful. Over the SEAS portion of the track, the RMSD between IX10 SSS and DEF SSS is $0.47 \mathrm{psu}$, which we believe is a reliable estimate of the DEF SSS quality; we consider this an acceptable error bar. However, we notice that a significant part of the water flow from the Bay of Bengal to SEAS goes through the Pamban Pass between India and Sri Lanka (see Fig. 1). As in Han and McCreary (2001), our model transport reaches a peak value of $\approx 1 \mathrm{~Sv}\left(1 \mathrm{~Sv} \equiv 10^{6} \mathrm{~m}^{3} \mathrm{~s}^{-1}\right)$ through the channel in November. That Han and McCreary (2001) used a different model, with a different forcing strategy, shows that this transport is a robust feature of the models having an open strait between India and Sri Lanka. One can wonder how realistic this "throughflow" value and the resulting salinity pattern are. The bathymetric chart of the Naval Hydrographic Office, India, shows that the strait is $\approx 0.5 \mathrm{~m}$ deep on average and $\approx 50 \mathrm{~km}$ wide. Given the along-channel maximal southward wind speed of $\approx 10 \mathrm{~m} \mathrm{~s}^{-1}$ (Luis and Kawamura 2000) and assuming that the bottom sediments roughness is very small, a rough calculation shows that the equilibrium velocity in the strait cannot exceed $1 \mathrm{~m} \mathrm{~s}^{-1}$. This implies that our model overestimates the transport through the strait by two orders of magnitude.

\section{2) Effect of Pamban Pass flow}

Since the actual transport through Pamban Pass is negligible compared to the DEF run transport, we close 

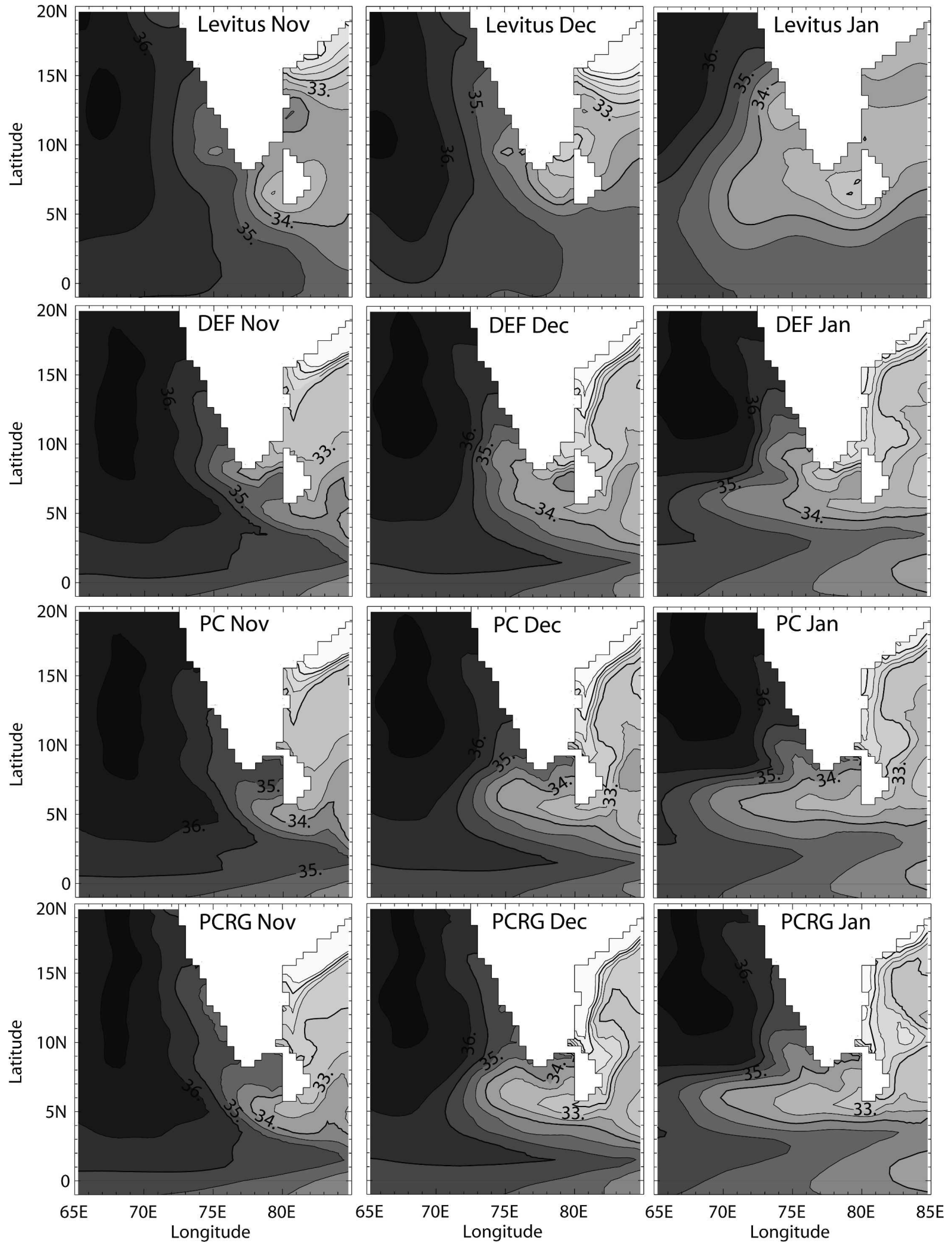

FIG. 2. Evolution of SSS in the southeastern Arabian Sea from November to January for (first row) the Levitus (1998) dataset, (second row) the DEF run, (third row) the PC run, and (fourth row) the PCRG run. Isocontours are every 0.5 psu. Only isocontours above 30 psu are drawn. 
it in the model. The resulting run is named "Pamban Pass Closed" (PC) and its SSS is presented in Fig. 2 (third row). Consistently with the conclusions of Han and McCreary (2001), we note a less pronounced inflow of freshwater into the SEAS. For instance, unlike in DEF, the 34-psu isohaline no longer reaches the western coast of India in PC. Closing the Pamban Pass raises the SEAS SSS RMSD between Levitus (1998) (IX10) and the model to $0.81 \mathrm{psu}(0.49 \mathrm{psu})$. Since the PC bathymetry is more realistic than DEF bathymetry, that the simulated SSS is poorer in PC suggests that some other zeroth-order problems remain in the model. It could be the physics itself that is not resolved accurately enough. Typically, it is believed that a significant part of the Arabian Sea and Bay of Bengal exchange of salt occurs through the Indian coastal currents (Jensen 2001). These currents are trapped at the coast within one Rossby deformation radius (Shankar et al. 1996), that is, $\approx 100 \mathrm{~km}$ at $10^{\circ} \mathrm{N}$, and our model grid size of 55 $\mathrm{km}$ might be too large to resolve them accurately. It could also be that the salinity advected by the currents is erroneous owing to incorrect interior ocean forcing by precipitation and evaporation fluxes ( $\mathrm{Yu}$ and $\mathrm{Mc}-$ Creary 2004). Incorrect salinity forcing at the coast by river runoff could also be held responsible for the erroneous salinity modeled (Han et al. 2001). It is this last possibility that we investigate next.

\section{3) EFFECT OF RUNOFF FORCING}

Even though a considerable part of the Indian subcontinent rainfall occurs south of $15^{\circ} \mathrm{N}$ (Xie and Arkin 1997), none of the corresponding watersheds is accounted for in the UNESCO (1996) product used in DEF and PC (Fig. 3a). The recent study by $\mathrm{Yu}$ and McCreary (2004) suggests that these south India runoffs could be an important forcing factor of the northern Indian Ocean SSS. We test the impact of this runoff using the more comprehensive runoff dataset of Fekete et al. (2000) (Fig. 3b; available from A. Dai's Web site at http://www.cgd.ucar.edu/cas/adai/data-dai.html), which is based on the discharge dataset from the Global Runoff Data Centre (GRDC). The annual mean runoff integrated over the northern Indian Ocean amounts to 5.96. $\times 10^{-2} \mathrm{~Sv}\left(9.68 \times 10^{-2} \mathrm{~Sv}\right)$ in UNESCO (GRDC) product. The resulting run forced with GRDC product is named "Pamban Pass Closed and Runoff from GRDC" (PCRG). PCRG SSS is presented in the fourth row of Fig. 2. As expected, switching to this more comprehensive runoff has an overall freshening impact on the basin. The fresh tongue originating from the bay and entering the SEAS has roughly the same pattern in PCRG and in PC, but it is significantly fresher in PCRG. The SEAS SSS RMSD between Levitus (1998)

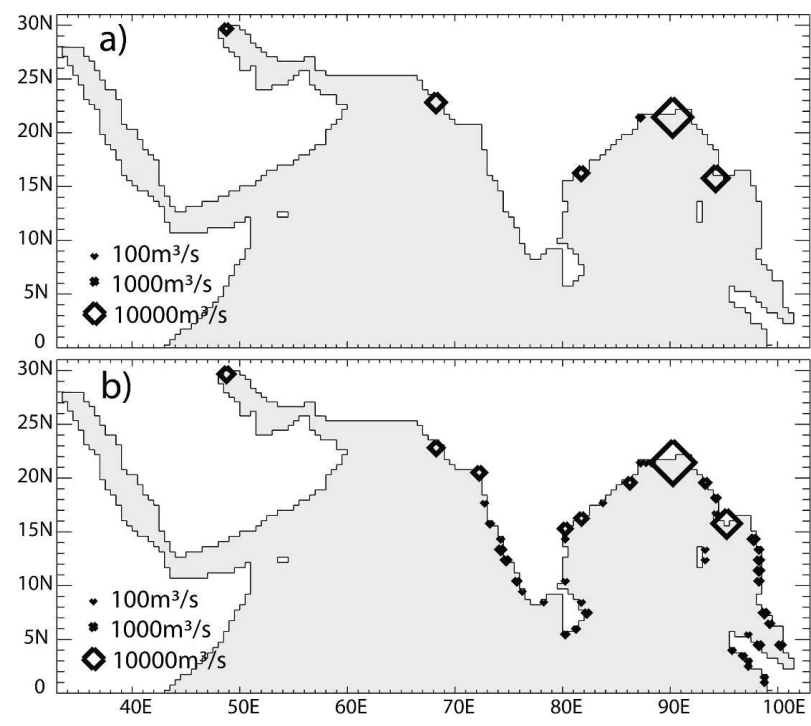

FIG. 3. Distribution of (a) UNESCO and (b) GRDC runoffs used to force the model. Square's area is proportional to runoff's magnitude.

(IX10) and PCRG is reduced to 0.69 psu (0.43 psu). Though there is still some possibility of improving the model SSS in the SEAS, maybe by increasing the model resolution, this is beyond the scope of the present paper. In particular, that PCRG yields the best statistics of the entire set of simulations as compared to IX10 climatology gives us some confidence in using it for investigating the salinity effects it simulates. Hence, in the rest of the paper, we use only PCRG.

\section{Barrier layer simulated by the model}

As mentioned in the introduction, the SEAS is known for the occurrence of a large-scale, consistent temperature inversion in the upper ocean during winter (e.g., Shankar et al. 2004). This feature, being stable at seasonal time scale, implies that it is associated with a sharp haline stratification of the warm layer, that is, a $\mathrm{BL}$. The BL thickness in the SEAS is $\approx 40 \mathrm{~m}$ from January to March (Rao and Sivakumar 2003, hereafter RS03). We define the BL thickness in our model outputs by computing the difference between the depth at which temperature becomes cooler than SST $-1^{\circ} \mathrm{C}$ and the depth at which the salt effects on density are equivalent to this $1^{\circ} \mathrm{C}$ drop, as in RS99. As in Durand et al. (2004), our model simulates a BL in the SEAS in qualitative agreement with the observed pattern of RS03, with a thickening in January and a collapse in April (not shown). However, one must be very cautious in attempting to validate the BL pattern in the model with RS03 estimates, as the available salinity subsurface 


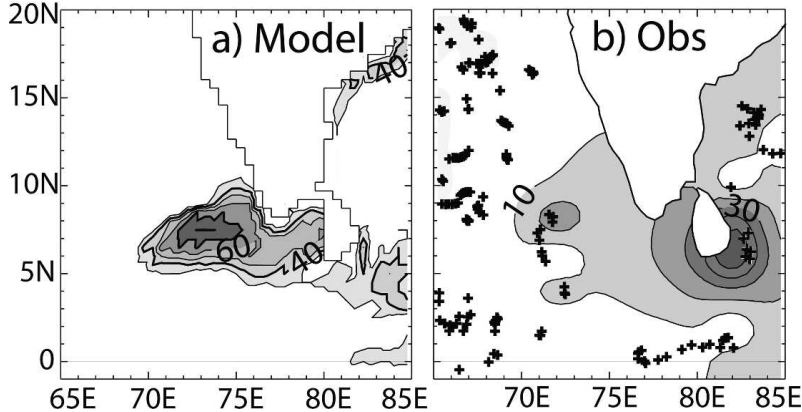

FIG. 4. (a) Simulated barrier-layer thickness on 29 December. Isocontours are every $10 \mathrm{~m}$. Only values above $30 \mathrm{~m}$ are plotted. (b) Observed barrier-layer thickness for December. Isocontours are every $10 \mathrm{~m}$. Observations locations are marked with crosses. Note the different gray scales in (a) and (b).

observations available at that time did not allow them to depict the $\mathrm{BL}$ at the scale of our area of interest. Hence, we decided to consider the latest BL climatology assembled by de Boyer Montégut (2007a, hereafter BMLC). This climatology differs from RS03 in that it includes the latest conductivity-temperature-depth (CTD) profiles due to the Array for Real-Time Geostrophic Oceanography (ARGO) program. Even though the data coverage is far from sufficient (see in particular the central SEAS; Fig. 4b), it is much better than the previous available climatologies. Also, BMLC computed BL thickness on a profile-wise basis whereas RS03 computed it from gridded fields of temperature and salinity. It has been shown that BL thickness computed from gridded temperature and salinity observations can be somewhat erroneous (de Boyer Montégut et al. 2004). Our model BL thickens in the SEAS during December (not shown; see D04, their Fig. 2). At the end of December, the core of the BL patch is located at $8^{\circ} \mathrm{N}, 73^{\circ} \mathrm{E}$ and its maximum thickness reaches $70 \mathrm{~m}$ (Fig. 4a). It extends zonally from Indian and Sri Lankan west coasts to about $70^{\circ} \mathrm{E}$. The observed pattern (Fig. $4 \mathrm{~b}$ ) is in broad agreement with the model, but there are still data gaps at the scale of the SEAS that prevent a thorough validation of BL thickness. Interestingly, the western and eastern edges of the thick BL patch are fairly well sampled by the available CTD profiles, and these BL thickness gradients are well positioned by the model. Nonetheless, the model BL thickness is significantly larger than the $20 \mathrm{~m}$ of the observed climatology. The reason for this is not clear. On the one hand, it suggests that the model probably overestimates the BL thickness. On the other hand, the limited amount of temperature and salinity profiles available to BMLC over the area of interest leaves open the issue of the realism of the BL thickness they mapped. First, examining the individual profiles they used, it appears that a 40-m-thick BL can easily occur at some time (not shown). Second, the typical thickness of the temperature inversion layer reported by TG92 is $\approx 35 \mathrm{~m}$, comparable to the thickness during winter 2002/03 (Shankar et al. 2004, their Fig. 3). The tropical oceans are known to be free of compensated layers, in the sense that the subsurface temperature maximum is not likely to be associated with a subsurface salinity maximum (BMLC). This means that the thickness of the temperature inversion layer can be considered as a lower bound for barrier-layer thickness. This also pleads for a typical value of the BL thickness of about $40 \mathrm{~m}$ in the real ocean. Overall, that the model captures the BL reasonably well enables us to use it to analyze the processes underlying its formation.

\section{Barrier-layer formation process}

Based on observational studies and the lack of surface cooling in the SEAS, TG92 and Shankar et al. (2004) suggested that the surface waters are cooled en route to the SEAS. We test this hypothesis in this section. We do this using an Eulerian analysis of the BL formation process and a Lagrangian tracking of the water masses involved in the $\mathrm{BL}$ formation.

\section{a. Eulerian approach}

Figure 5a presents the longitude-time evolution of BL thickness along the zonal axis of the patch (around $6^{\circ} \mathrm{N}$ ) discussed in the previous section. It appears that the BL thickening is swift throughout the section, the thickness jumping from $\approx 0$ to $50 \mathrm{~m}$ in a few days. The westward progression of the BL thickening shows a coherent propagation pattern. This BL thickening is caused both by the rise of the top of pycnocline (Fig. $5 \mathrm{~b}$ ) and by the deepening of the top of thermocline (Fig. 5c). The latter occurs some 1 to 2 weeks later, however, and is more continuous in time. This is suggestive of two different dynamic processes acting at the bottom of the mixed layer and at the bottom of the isothermal layer. Why does the top of pycnocline shoal and the top of thermocline deepen? The longitudetime evolution of temperature and salinity (Fig. 6) offers an insight into this issue. Evolution of salinity in the upper layer (0-30 m, representative of the mixed layer) closely resembles the BL thickness pattern, with a rapid drop of $\approx 2$ psu starting in the east and coherently progressing westward (Fig. 6a), as in the observations (Shankar et al. 2004). The mixed layer temperature gradually decreases during the period, again following a predominant east to west march (Fig. 6b). As such, it acts to densify the mixed layer and does not participate in the shoaling of the pycnocline. Temperature varia- 


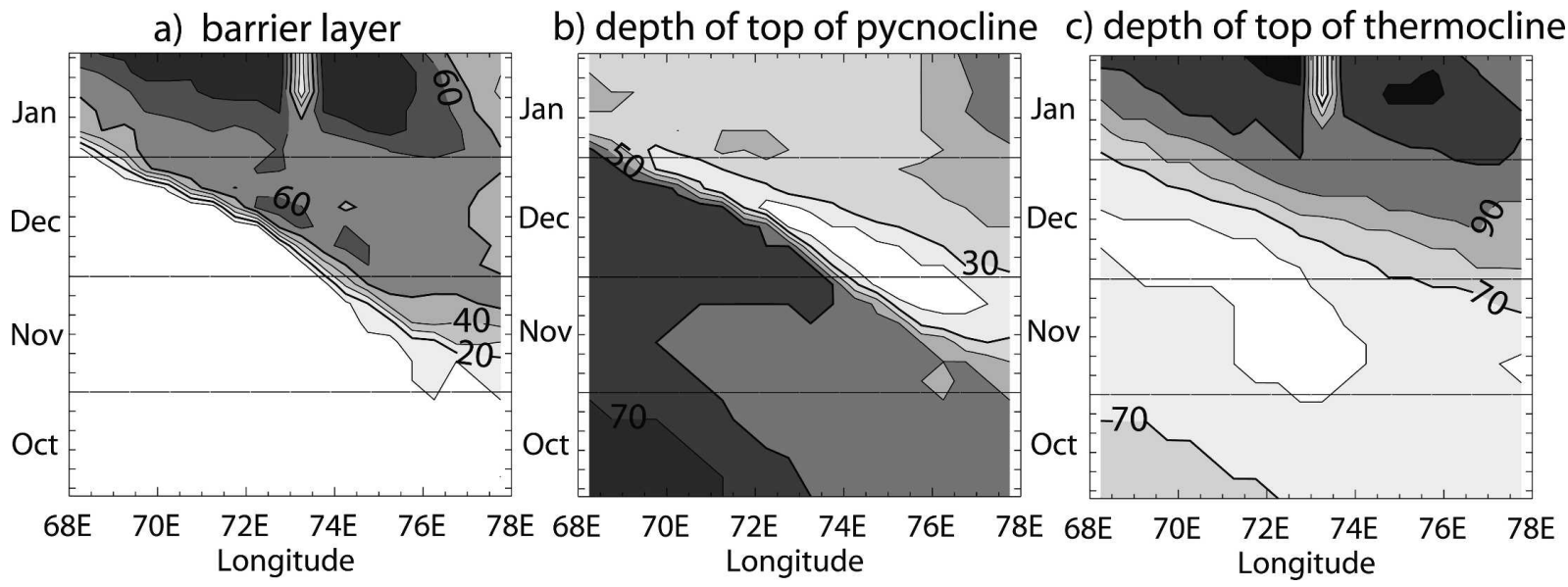

FIG. 5. Longitude-time plot of simulated (a) barrier-layer thickness, (b) depth of top of pycnocline, and (c) depth of top of thermocline along $6^{\circ} \mathrm{N}$. Isocontours are every $10 \mathrm{~m}$.

tion of the 30-80-m layer (representative of the BL) appears well correlated with the depth of top of thermocline (cf. Fig. 5c and Fig. 6c). This layer warms by about $0.6^{\circ} \mathrm{C}$ in 1.5 months, and the warming again propagates westward. Visual comparison of Figs. $6 b$ and $6 \mathrm{c}$ clearly shows that the entire section exhibits a marked $\left(>0.2^{\circ} \mathrm{C}\right)$ temperature inversion from late December onward. It is this inversion that, along with surface heating by air-sea fluxes, drives the premonsoonal SST buildup in the forthcoming months (D04). The inversion also propagates westward, as suggested by Shankar et al. (2004) based on XBT observations along $10^{\circ} \mathrm{N}$. Overall, the variations of temperature and salinity in the density-mixed layer and in the pycnocline suggest the following scenario: the top of pycnocline shoals owing to the arrival of fresh (though relatively cold) water at the surface; a few days later, the top of thermocline deepens owing to the appearance of warm water at subsurface levels. The combination of the two processes builds up the temperature inversion.

At this stage, one cannot discriminate between advective, wave-induced, or locally forced processes to explain the drastic change in the thermohaline structure simulated. To unveil this, we investigate the evolution of zonal and vertical velocity over the area (Fig. 7). We present the zonal current along $5^{\circ} \mathrm{N}$ in order to better understand the evolution of the thermodynamics along $6^{\circ} \mathrm{N}$ because of the known moderate northward transport associated with the Winter Monsoon Current (WMC) over the SEAS at this time of the year (Schott and McCreary 2001; Shankar et al. 2002). The zonal current exhibits the same pattern as upper-layer salinity variation, with a westward current of $\approx 0.4 \mathrm{~m} \mathrm{~s}^{-1}$ propagating westward. We know that this area is affected by a) $\operatorname{Sin}[0,30 \mathrm{~m}]$

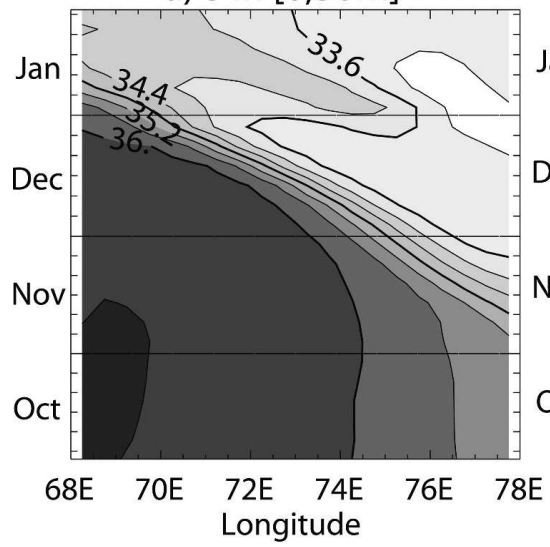

b) $\mathrm{T}$ in $[0,30 \mathrm{~m}]$

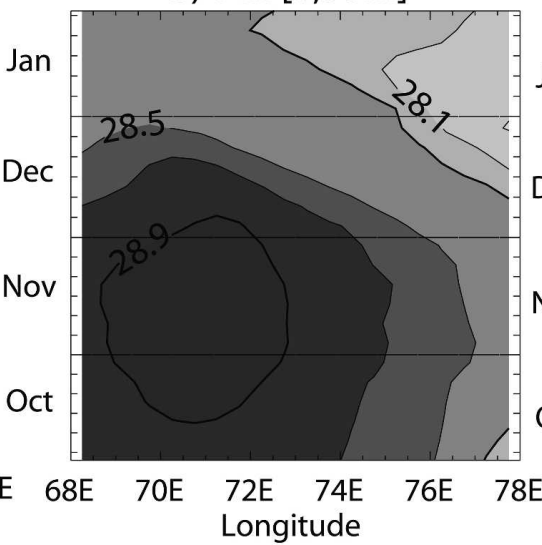

c) $\operatorname{Tin}[30 \mathrm{~m}, 80 \mathrm{~m}]$

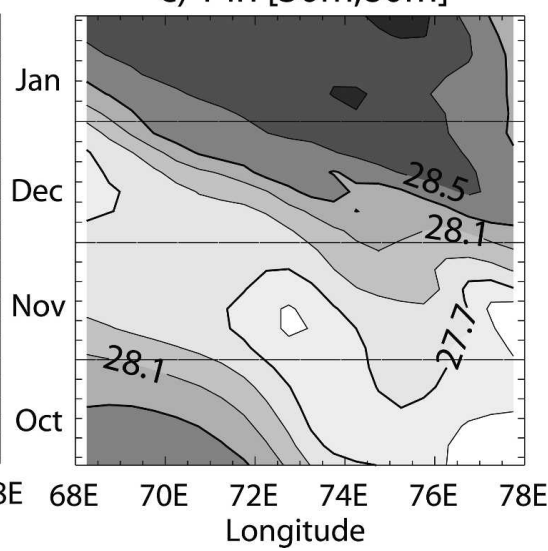

FIG. 6. Longitude-time plot of simulated (a) salinity in the 0-30-m layer, (b) temperature in the 0-30-m layer, and (c) temperature in the $30-80-\mathrm{m}$ layer along $6^{\circ} \mathrm{N}$. Isocontours are every $0.4 \mathrm{psu}$ and $0.2^{\circ} \mathrm{C}$. Grayscale is the same for the two temperature plots. 


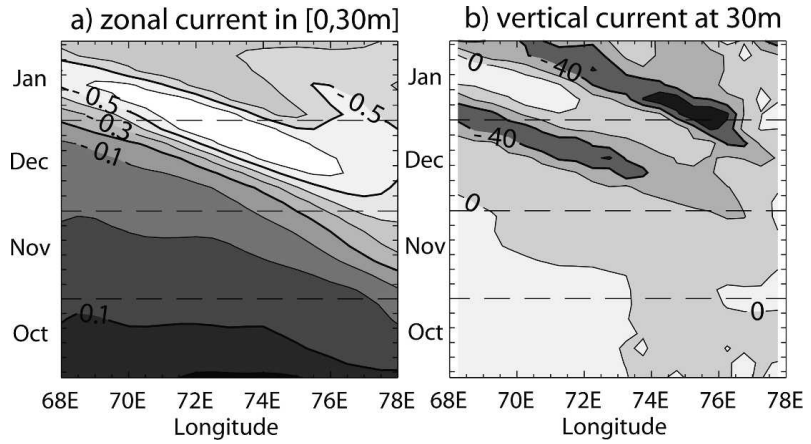

FIG. 7. Longitude-time plot of simulated (a) zonal current in the $0-30-\mathrm{m}$ layer along $5^{\circ} \mathrm{N}$ and (b) vertical velocity at $30 \mathrm{~m}$ along $6^{\circ} \mathrm{N}$. Isocontours are every $0.1 \mathrm{~m} \mathrm{~s}^{-1}$ and $20 \mathrm{~m} \mathrm{month}^{-1}$, respectively.

Rossby wave packets originating from the west coast of India (McCreary et al. 1993). Shankar and Shetye (1997) demonstrated that this westward-propagating westward current along $5^{\circ} \mathrm{N}$ can be explained in a linear framework, and that it is basically driven by the collapse of the winds along the east coast of India a few months earlier. We estimated the propagation speed of the zonal current at $0.34 \mathrm{~m} \mathrm{~s}^{-1}$. This is roughly consistent with the phase speed of $0.38 \mathrm{~m} \mathrm{~s}^{-1}$ of the first baroclinic mode Rossby waves computed by Brandt et al. (2002) from hydrographic cruises along $8^{\circ} \mathrm{N}$. This westward current seems to be responsible for the advection of the fresh salinity tongue in the upper layer from the east to the west. The vertical velocity at the bottom of the mixed layer exhibits a distinct pattern, though characterized by a marked westward propagation at the same speed as well (Fig. 7b). It presents two successive downwelling bursts, one originating at the eastern edge of the section in late November and the other lagging by about 3 weeks. The duration of the downwelling events (about two events of 15 days each) and their order of magnitude (about $40 \mathrm{~m} \mathrm{month}^{-1}$ ) is likely to account for the warm water transfer from the upper $(0-30 \mathrm{~m})$ to the underlying $(30-80 \mathrm{~m})$ layer. The next section aims at giving clearer insight into the respective part played by advective and wave-driven processes in the formation of the BL.

\section{b. Lagrangian analysis}

To trace back the water masses involved in the BL formation process, we use the offline Lagrangian trajectory analysis tool of Blanke and Raynaud (1997). To do so, we initialize one batch of 36 particles in the mixed layer (ML) and another batch in the BL on 29 December. The particle positions are defined as one per model grid point in the box $\left(6^{\circ}-7.5^{\circ} \mathrm{N}, 71^{\circ}-75^{\circ} \mathrm{E}\right)$

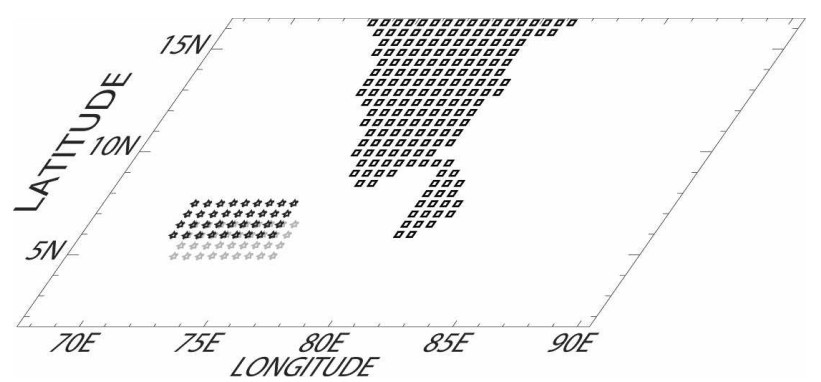

FIG. 8. Layout of the Lagrangian particles traced back in the model. ML batch is released at $15 \mathrm{~m}$ (black stars); BL batch is released at $55 \mathrm{~m}$ (gray stars).

(Fig. 8) encompassing the patch of thick BL at this time (Fig. 4a). Their depth is $15 \mathrm{~m}(55 \mathrm{~m})$ for the ML (BL) batch. At this time, we integrate the particle trajectories backward in time for 3 months. Our approach is complementary to the modeling studies of Bruce et al. (1994) and Jensen (2001), who analyzed the water mass exchanges between Arabian Sea and Bay of Bengal by tracking passive tracer transport in their circulation models. They released the tracer in the upper layer of the northern Bay of Bengal, and let it be advected by the model currents forward in time. Bruce et al. (1994) in particular suggested that SEAS surface water in midJanuary has its origin in the Bay of Bengal three months earlier. Our backward-in-time Lagrangian approach allows tracing not only the trajectory but also the thermal and haline conditions of the particles characteristics along their streamlines (Blanke et al. 1999).

The ML batch undergoes an upwelling process over the 3 months (late September to late December), all particles originating from depths of about $30-50 \mathrm{~m}$ (Fig. 9a) irrespective of their geographical origin. It turns out that $1 / 4$ of the particles come from East India Coastal Current, 1/4 come from the southwestern Bay of Bengal, and $1 / 2$ recirculate in the SEAS. Figure $9 b$ shows that after these three branches merge, the surface water mass is significantly cooled in the WMC south and east of Sri Lanka. The cooling takes place in late November (not shown). The bulk formula calculation of the heat fluxes by our model yields a pronounced $\left(-20 \mathrm{~W} \mathrm{~m}^{-2}\right)$ net heat loss in the area in November. This could be linked with the local maximum of cloudiness over the area from October to November (Berliand and Strokina 1980).

The net heat flux estimated by Josey et al. (1996), however, remains positive $\left(\approx 30\right.$ to $\left.40 \mathrm{~W} \mathrm{~m}^{-2}\right)$ south and east of Sri Lanka in November. The cooling in this climatology, as also in the climatology of Rao and Sivakumar (1999), occurs instead in the western Bay of Bengal in November and off the southern tip of India and west of Sri Lanka, in December (Shankar et al. 

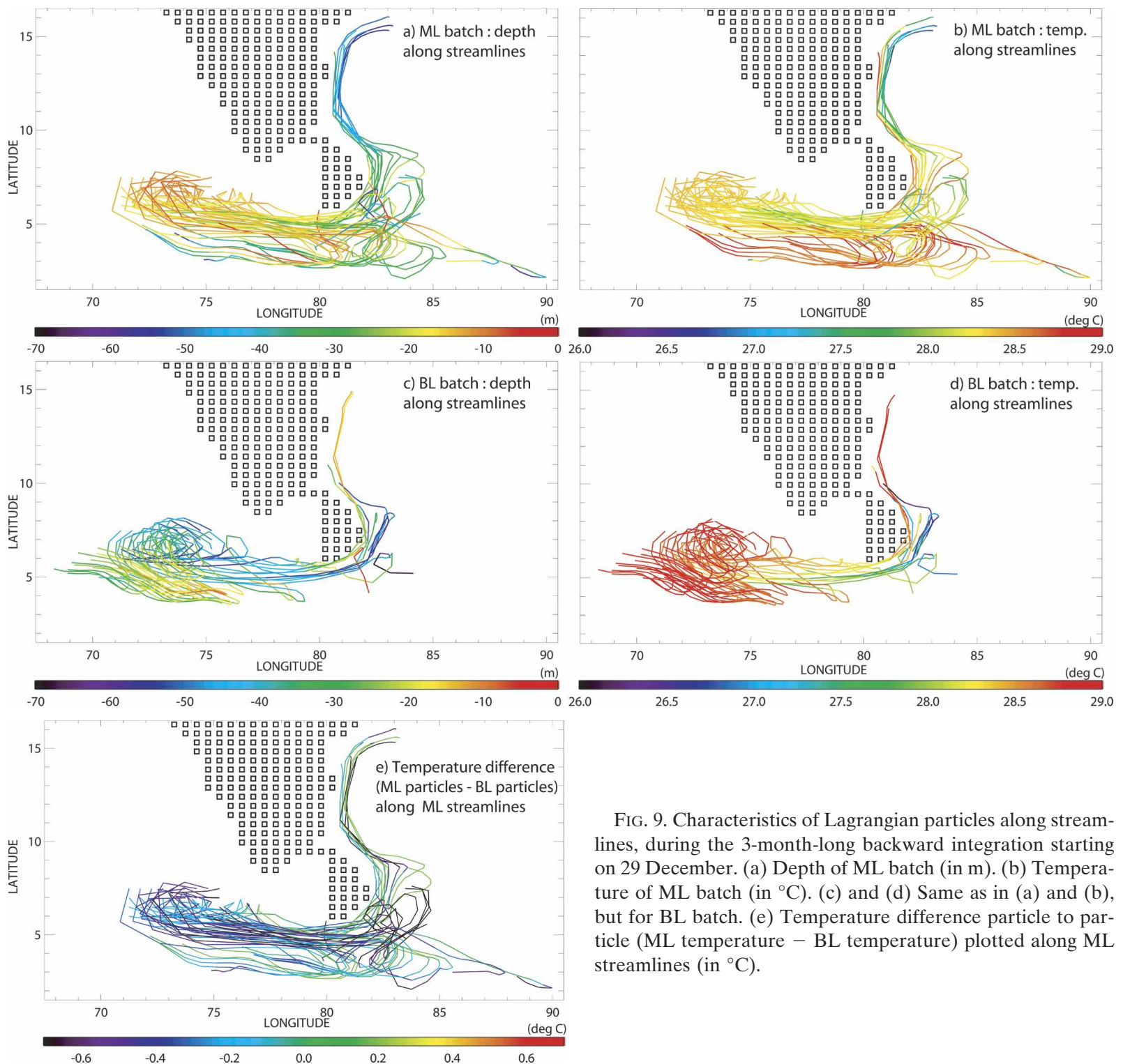

FIG. 9. Characteristics of Lagrangian particles along streamlines, during the 3-month-long backward integration starting on 29 December. (a) Depth of ML batch (in m). (b) Temperature of ML batch (in ${ }^{\circ} \mathrm{C}$ ). (c) and (d) Same as in (a) and (b), but for BL batch. (e) Temperature difference particle to particle (ML temperature - BL temperature) plotted along ML streamlines (in $\left.{ }^{\circ} \mathrm{C}\right)$.

2004). The cooling in the western Bay of Bengal in November can cool only the low-salinity waters that originate in the northern Bay of Bengal (1/4 of the particles). The cooling south of India and west of Sri Lanka was identified by Luis and Kawamura (2000) to explain the $1.2^{\circ} \mathrm{C} \mathrm{SST}$ drop they observed there during the second half of December. The reason why the model fails to simulate the cooling over this area appears to stem from its wind stress forcing flux, which is too weak to drive significant latent heat loss at ocean surface (not shown). This latent heat flux can cool the particles originating in the southwestern Bay of Bengal (1/4 of the particles) and cool further the waters from the northern Bay of Bengal. This cooling, however, does not impact the SEAS SST much in the model because the BL effects and local surface heating by air-sea fluxes in the SEAS rewarm the surface in the following 4 months (D04).

The BL batch presents a completely different behavior. About 2/3 of the particles are downwelled locally (Fig. 9c), and the downwelled water mass has been warm (over $28.5^{\circ} \mathrm{C}$ ) for at least the 3-month-long period of the tracking experiment (Fig. 9d).

Although the primary purpose of our study is to ascertain the BL buildup mechanism, it is tempting to investigate the temperature inversion formation process. To trace back the origin of the temperature inversion, we go back to the layout of the Lagrangian particles (Fig. 8): on 29 December, at each of the 36 positions (latitude, longitude) selected, we had a couple of 
Lagrangian particles, one being part of ML batch situated at $15 \mathrm{~m}$, and another being part of BL batch situated at $55 \mathrm{~m}$. It turns out that at this time, for each of the 36 particle couples, the ML particle is cooler than the underlying $\mathrm{BL}$ particle. Where and when does this temperature inversion come from? To get insight into this, we computed the temperature difference (ML BL) for each of the 36 particle couples, and plotted it along the ML streamlines (Fig. 9e). It appears that the temperature inversion mostly has its origin in November, east and south of Sri Lanka. It is generated by the surface cooling mentioned above. The magnitude and location of the temperature inversion in the model has been extensively validated in the SEAS (D04). It gives some confidence in the fact that, somehow, the surface water mass originating in the Bay of Bengal does undergo a cooling en route to SEAS. The latest available climatologies locate a prominent cooling in December west of Sri Lanka and south of India. This feature appears as a good candidate to account for the temperature inversion formation, as it is located downstream of the junction of the three branches of the surface circulation bound for the SEAS.

\section{Concluding remarks}

In this study, we used a numerical model to investigate the salinity effects in the SEAS. A preliminary step was to ensure that the salinity field simulated by the model is realistic enough. This required closing the Pamban Pass between India and Sri Lanka, and introducing a comprehensive runoff forcing throughout the northern Indian Ocean coasts. Then we investigated the BL formation process in the SEAS in winter, following successively an Eulerian and a Lagrangian approach. The two approaches appear complementary and provide the mechanism illustrated by Fig. 10 for the BL formation. In November, three branches of the upper-ocean circulation merge in the southwestern Bay of Bengal. Soon after, the water mass is cooled by atmospheric heat fluxes en route to SEAS. The exact magnitude, timing, and location of this cooling remains a matter of debate, as the model is basically inconsistent with independent estimates of ocean-atmosphere heat fluxes. It is however conducive to the temperature inversion buildup in late December in the SEAS. Indeed, the cooled and fresh surface water mass is advected by the westward-propagating westward currents associated with a Rossby wave front originating from the Indian and Sri Lankan west coasts. At the same time, the warm and saline SEAS surface water is downwelled by two successive Rossby wave fronts. The simultaneity of arrival of fresh and cool Bay of Bengal water and

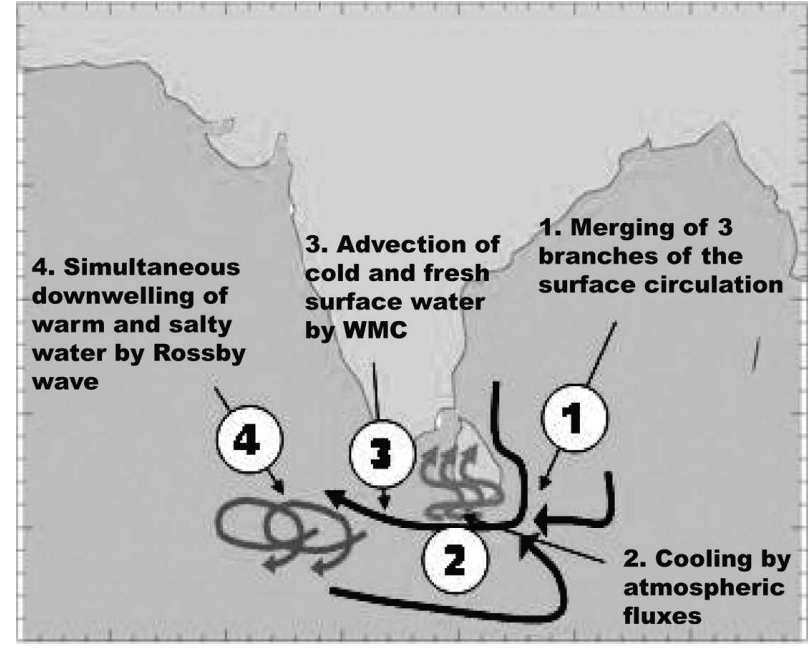

FIG. 10. Schematic of the barrier-layer formation process.

downwelling of warm and salty Arabian seawater in the SEAS in late December provides the perfect ground for the temperature inversion buildup, sustained by the thick BL. One should be cautious, however, with regard to the thickness of the BL simulated by the model: as it is very hard to validate from in situ observations, the present study should be considered as qualitative rather than quantitative. It means that our model simulation sheds light on the sequence of events leading to BL buildup, rather than on the magnitude of the individual processes synthesized in Fig. 10. The BL is annihilated before the onset of the summer monsoon by upwelling Rossby wave fronts, which are also radiated from the west coasts of India and Sri Lanka, and by the arrival of high-salinity waters from the north; these processes are also forced remotely (Shenoi et al. 2004, 2005). Thus, two sets of processes, which act oppositely but are forced similarly by the annual cycle of winds, freshwater runoff from rivers, and precipitation and evaporation over the ocean, act to form the barrier layer during winter and then to annihilate it as the summer monsoon sets in. In between, the dynamics of the region ensure that the low-salinity waters, the temperature inversions, and even the currents themselves shift westward across the SEAS owing to Rossby wave radiation from the west coasts of India and Sri Lanka. We also know that the $\mathrm{BL}$ reinjects heat trapped at subsurface levels into the surface ML (D04). This is conducive to the buildup of the warm pool, with SSTs exceeding $30^{\circ} \mathrm{C}$ in May prior to summer monsoon onset. It is believed that the thermohaline structure of the SEAS warm pool is crucial to the coupled ocean-atmosphere interactions triggering summer monsoon onset (Masson et al. 2005). Given the vulnerability of populations surrounding the 
northern Indian Ocean to summer monsoon rainfall supply, understanding the year-to-year variability of summer monsoon onset process, and in particular its timing, is a key issue. Drawing a link between the SEAS thermodynamics and the wave-driven circulation of the northern Indian Ocean, our study suggests that the picture should be predictable to some extent. Investigating the year-to-year variability of the mechanism revealed by this study in a climatological framework will be the next stage of our investigations.

Acknowledgments. We are indebted to S. R. Shetye, who initiated most of this study. Fruitful discussions with J. Vialard helped a lot. We thank J.-M. Molines and A.-M. Tréguier for sharing their insights into the OGCM setup. C. Ethé provided the OGCM forcing fields. SAXO, the plotting software developed by S. Masson, was extensively used. The OGCM experiments were carried out on the IBM P690 of CNES-Toulouse; support from this institution is gratefully acknowledged. DS and SSCS thank DOD and DST, India, for financial support. This study was conducted under Indo-French Programme of Research in Weather and Climate (IFPREWAC).

\section{REFERENCES}

Bentamy, A., Y. Quilfen, F. Gohin, N. Grima, M. Lenaour, and J. Servain, 1996: Determination and validation of average wind fields from ERS-1 scatterometer measurements. Global Atmos. Ocean Syst., 4, 1-29.

Berliand, M. E., and T. G. Strokina, 1980: Global Distribution of the Total Amount of Clouds. Hydrometeorological Publishing House, $71 \mathrm{pp}$.

Blanke, B., and P. Delecluse, 1993: Variability of the tropical Atlantic Ocean simulated by a general circulation model with two different mixed layer physics. J. Phys. Oceanogr., 23, 1363-1388.

— Undercurrent: An Eulerian and Lagrangian approach for GCM results. J. Phys. Oceanogr., 27, 1038-1053.

_- M. Arhan, G. Madec, and S. Roche, 1999: Warm water paths in the equatorial Atlantic as diagnosed with a general circulation model. J. Phys. Oceanogr., 29, 2753-2768.

Brandt, P., L. Stramma, F. Schott, J. Fischer, M. Dengler, and D. Quadfasel, 2002: Annual Rossby waves in the Arabian Sea from TOPEX/Poseidon altimeter and in situ data. Deep-Sea Res. II, 49, 1197-1210.

Bruce, J. G., D. R. Johnson, and J. C. Kindle, 1994: Evidence for eddy formation in the eastern Arabian Sea during the northeast monsoon. J. Geophys. Res., 99, 7651-7664.

de Boyer Montégut, C., G. Madec, A. S. Fischer, A. Lazar, and D. Iudicone, 2004: Mixed layer depth over the global ocean: An examination of profile data and a profile-based climatology. J. Geophys. Res., 109, C12003, doi:10.1029/2004JC002378.

_ J. Mignot, A. Lazar, and C. Cravatte, 2007a: Control of salinity on the mixed layer depth in the world ocean. Part I: General description. J. Geophys. Res., in press.
- J. Vialard, F. Durand, and G. Madec, 2007b: Simulated seasonal and interannual variability of the mixed layer heat and salinity budget in the northern Indian Ocean. J. Climate, in press.

Delcroix, T., A. Dessier, Y. Gouriou, and M. McPhaden, 2005: Time and space scales for sea surface salinity in the tropical oceans. Deep-Sea Res., 52, 787-813.

Durand, F., S. R. Shetye, J. Vialard, D. Shankar, S. S. C. Shenoi, C. Ethe, and G. Madec, 2004: Impact of temperature inversions on SST evolution in the southeastern Arabian Sea during the pre-summer monsoon season. Geophys. Res. Lett., 31, L01305, doi:10.1029/2003GL018906.

Fekete, B. M., C. J. Vorosmarty, and W. Grabs, 2000: Global composite runoff fields based on observed river discharge and simulated water balances. Documentation for UNH-GRDC Composite Runoff Fields, v.1.0, Global Runoff Data Centre, Koblenz, Germany, 39 pp.

Gopalakrishna, V. V., Z. Johnson, G. Salgaonkar, K. Nisha, C. K. Rajan, and R. R. Rao, 2005: Observed variability of sea surface salinity and thermal inversions in the Lakshadweep Sea during contrast monsoons. Geophys. Res. Lett., 32, L18605, doi:10.1029/2005GL023280.

Han, W., and J. P. McCreary, 2001: Modeling salinity distributions in the Indian Ocean. J. Geophys. Res., 106, 859-877.

,-- , and K. E. Kohler, 2001: Influence of precipitation minus evaporation and Bay of Bengal rivers on dynamics, thermodynamics, and mixed layer physics in the upper Indian Ocean. J. Geophys. Res., 106, 6895-6916.

Jensen, T. G., 2001: Arabian Sea and Bay of Bengal exchange of salt and tracers in an ocean model. Geophys. Res. Lett., 28, 3967-3970.

Joseph, P. V., 1990: Warm pool over the Indian Ocean and monsoon onset. Trop. Ocean-Atmos. Newslett., 53, 1-5.

Josey, S. A., E. C. Kent, D. Oakley, and P. K. Taylor, 1996: A new global air-sea heat and momentum flux climatology. International WOCE Newsletter, Vol. 24, WOCE International Project Office, Southampton, United Kingdom, 3-5.

Kalnay, E., and Coauthors, 1996: The NCEP/NCAR 40-Year Reanalysis Project. Bull. Amer. Meteor. Soc., 77, 437-471.

Levitus, S., 1998: Climatological Atlas of the World Ocean. NOAA Prof. Paper 13, 173 pp. and 17 microfiche.

Luis, A. J., and H. Kawamura, 2000: Wintertime wind forcing and sea surface cooling near the south India tip observed using NSCAT and AVHRR. Remote Sens. Environ., 73, 55-64.

Lukas, R., and E. Lindstrom, 1991: The mixed layer of the western equatorial Pacific Ocean. J. Geophys. Res., 96, 3343-3358.

Madec, G., P. Delecluse, M. Imbard, and C. Levy, 1998: OPA 8.1 Ocean General Circulation Model reference manual. Note du Pole de Modélisation, No. 11, Institut Pierre-Simon Laplace, France, 91 pp.

Masson, S., and Coauthors, 2005: Impact of barrier layer on winter-spring warming of the South-Eastern Arabian Sea. Geophys. Res. Lett., 32, L07703, doi:10.1029/2004GL021980.

McCreary, J. P., P. K. Kundu, and R. L. Molinari, 1993: A numerical investigation of the dynamics, thermodynamics and mixed-layer processes in the Indian Ocean. Progress in Oceanography, Vol. 31, Pergamon Press, 181-244.

Rao, R. R., and R. Sivakumar, 1999: On the possible mechanisms of the evolution of a mini-warm pool during the pre-summer monsoon season and the onset vortex in the southeastern Arabian Sea. Quart. J. Roy. Meteor. Soc., 125, 787-809. 
$\longrightarrow$, and — 2003: Seasonal variability of sea surface salinity and salt budget of the mixed layer of the north Indian Ocean. J. Geophys. Res., 108, 3009, doi:10.1029/2001JC000907.

Reynolds, D., and T. Smith, 1994: Improved global sea surface temperature analyses using optimum interpolation. J. Climate, 7, 929-948.

Schott, F., and J. P. McCreary, 2001: The monsoon circulation in the Indian Ocean. Progress in Oceanography, Vol. 51, Pergamon Press, 1-123.

Shankar, D., and S. R. Shetye, 1997: On the dynamics of the Lakshadweep high and low in the southeastern Arabian Sea. $J$. Geophys. Res., 102, 12 551-12 562.

— J. J. McCreary, W. Han, and S. R. Shetye, 1996: On the dynamics of the East India Coastal Current. Part 1, Analytic solutions forced by interior Ekman pumping and local alongshore winds. J. Geophys. Res., 101, 13 975-13 991.

_ - P. N. Vinayachandran, and A. S. Unnikrishnan, 2002: The monsoon currents in the north Indian Ocean. Progress in Oceanography, Vol. 52, Pergamon Press, 63-120.

— , V. V. Gopalakrishna, S. S. C. Shenoi, S. R. Shetye, C. K. Rajan, J. Zacharias, N. Araligidad, and G. S. Michael, 2004: Observational evidence for westward propagation of temperature inversions in the southeastern Arabian Sea. Geophys. Res. Lett., 31, L08305, doi:10.1029/2004GL019652.

Shenoi, S. S. C., D. Shankar, and S. R. Shetye, 1999: On the sea surface temperature high in the Lakshadweep Sea before the onset of the southwest monsoon. J. Geophys. Res., 104, $15703-15712$. $\longrightarrow, \ldots$, and $\longrightarrow, 2004$ : Remote forcing annihilates barrier layer in southeastern Arabian Sea. Geophys. Res. Lett., 31, L05307, doi:10.1029/2003GL019270.

— - - V. V. Gopalakrishna, and F. Durand, 2005: Role of ocean in the genesis and annihilation of the core of the warm pool in the southeastern Arabian Sea. Mausam, 56, 147-160.

Shetye, S. R., A. D. Gouveia, S. S. C. Shenoi, G. S. Michael, D. Sundar, A. M. Almeida, and K. Santanam, 1991: The coastal current off western India during the northeast monsoon. Deep-Sea Res., 38A, 1517-1529.

,-- D. Shankar, S. S. C. Shenoi, P. N. Vinayachandran, D. Sundar, G. S. Michael, and G. Nampoothiri, 1996: Hydrography and circulation in the western Bay of Bengal during the northeast monsoon. J. Geophys. Res., 101, 14 011-14 025.

Smith, W. H. F., and D. T. Sandwell, 1994: Bathymetric prediction from dense satellite altimetry and sparse shipboard bathymetry. J. Geophys. Res., 99, 21 803-21 824.

Thadathil, P., and A. K. Gosh, 1992: Surface layer temperature inversion in the arabian sea during winter. J. Oceanogr., 48, 293-304.

UNESCO, 1996: Discharge of Selected Rivers of the World. Vol. II (Part II).

Xie, P., and P. Arkin, 1997: Analyses of global monthly precipitation using gauge observations, satellite estimates, and numerical model predictions. J. Climate, 9, 840-858.

Yu, Z., and J. P. McCreary, 2004: Assessing precipitation products in the Indian Ocean using an ocean model. J. Geophys. Res., 109, C05013, doi:10.1029/2003JC002106. 